\title{
ЗАЩИТА СТАЛИ ОТ КОРРОЗИИ В КИСЛЫХ СРЕДАХ ИНГИБИТОРАМИ «СОЛИНГ» ПРИ ПОВЫШЕННЫХ ТЕМПЕРАТУРАХ
}

\author{
И.А. Меньшиков, Н.В. Лукьянова, А.Б. Шеин
}

Иван Александрович Меньшиков, Надежда Владимировна Лукьянова, Анатолий Борисович Шеин*

Кафедра физической химии, Пермский государственный национальный исследовательский университет, ул. Букирева, 15, Пермь, Российская Федерация, 614990

E-mail: ivanmenshikov574@gmail.com Anatoly173@yandex.ru, ashein@psu.ru*

В работе приведены результаты исследования защитного действия ряда ингибирующих композиций серии "СолИнг" на основе ацетиленовых спиртов и их смесей с азотсодержсащими соединениями различного типа в растворах серной и соляной кислот в интервале температур 20-60 ${ }^{\circ}$. Эл Электрохимические исследования выполнены на малоуглеродистой стали Ст3. Поляризационные кривые снимали в трехэлектродной ячейке ходом из катодной области в анодную со скоростью развертки потенциала 10 мВ/мин, используя электрохимический измерительный комплекс SOLARTRON 1280 С. Исследованы защитные композиции: СолИнг ИК-1 на основе ненасыщенного спирта в смеси с серосодержащим амидом в водной среде; СолИнг ИК-2 на основе ненасыщенного спирта с добавками четвертичной соли аммония и комплексона; СолИнг ИК-3 на основе ненасыщенного спирта в системе органических растворителей, а также СолИнг ИК-4(А) на основе высокомолекулярного азотсодержсащего ПАВ (молекулярной массы от 300 до 400) с добавками ненасыщенного спирта в системе органических растворителей и СолИнг ИК-4(Б) на основе высокомолекулярного азотсодержащего ПАВ с молекулярной массой до 300. Установлено, что во всем исследованном диапазоне температур композиции СолИнг ИК-2, ИК-4(А) и ИК-4(Б) обладают высоким защитным эффектом, что говорит об устойчивости адсорбционных слоев ингибитора с повышением температуры. Композиции ИК-1 и ИК-3 обладают меньшим защитным эффектом, но в целом рост температуры не оказывает сильного негативного влияния на величину защитного эффекта. Устойчивость исследуемых композиций объясняется наличием в их составе ненасыщенных спиртов, проявляющих высокие защитные характеристики при повышенных температурах. На основе полученных результатов были рассчитаны эффективные энергии активации коррозионного процесса.

Ключевые слова: серная кислота, соляная кислота, малоуглеродистая сталь, ингибитор, температура

\section{PROTECTION OF STEEL FROM CORROSION \\ IN ACIDIC MEDIA AT ELEVATED TEMPERATURES BY «SOLING» SERIES INHIBITORS}

\author{
I.A. Menshikov, N.V. Lukyanova, A.B. Shein
}

Ivan A. Menshikov, Nadezhda V. Lukyanova, Anatoliy B. Shein*

Department of Physical Chemistry, Perm State University, Bukireva st., 15, Perm, 614990, Russia

E-mail: ivanmenshikov574@gmail.com Anatoly173@yandex.ru, ashein@psu.ru*

The work presents the results of the study of a number of inhibitory compositions of the "Soling" series based on acetylenic alcohols and their mixtures with nitrogen-containing compounds of various types in a hydrochloric and sulfuric acid solutions at temperatures $20-60{ }^{\circ} \mathrm{C}$. Electrochemical studies were performed on mild steel St3. Polarization curves were obtained in a three-electrode cell, using the SOLARTRON 1280 C electrochemical measuring complex. The protective compositions were studied: Soling IK-1 on the basis of unsaturated alcohol in a mixture with sulfur-containing amide in an aqueous medium; Soling IK-2 on the basis of unsaturated alcohol with additions of quaternary ammonium salt and complexone; Soling IK-3 on the basis of 
unsaturated alcohol in the system of organic solvents, as well as Soling IK-4(A) on the basis of a high-molecular nitrogen-containing surfactant (molecular weight from 300 to 400) with additions of unsaturated alcohol in a system of organic solvents and Soling IK-4(B) based on a high-molecular nitrogen-containing surfactant with a molecular weight of up to 300. It has been obtained that Soling IK-2, IK-4(A) and IK-4(B) compositions have a high protective effect throughout the temperature range, which indicates the stability of the adsorption layers of the inhibitor with increasing temperature. Compositions IK-1 and IK-3 have less protective effect, but in general, the temperature increase does not have a strong negative effect on the magnitude of the protective effect. The stability of the compositions under study is explained by the presence in their composition of unsaturated alcohols showing high protective characteristics at elevated temperatures. Based on the results obtained, the effective activation energies of the corrosion process have been calculated.

Key words: hydrochloric acid solution, sulfuric acid solution, low-carbon steel, inhibitor, temperature

Для цитирования:

Меньшиков И.А., Лукьянова Н.В., Шеин А.Б. Защита стали от коррозии в кислых средах ингибиторами «СолИнг» при повышенных температурах. Изв. вузов. Химия и хим. технология. 2019. Т. 62. Вып. 4. С. 103-110

For citation:

Menshikov I.A., Lukyanova N.V., Shein A.B. Protection of steel from corrosion in acidic media at elevated temperatures by «Soling» series inhibitors. Izv. Vyssh. Uchebn. Zaved. Khim. Khim. Tekhnol. 2019. V. 62. N 4. P. 103-110

В практике противокоррозионной защиты ключевую роль играют ингибиторы коррозии, введение которых в агрессивную среду уже в малых количествах позволяет существенно снизить коррозионные потери металла и, как следствие, продлить эксплуатационный срок промышленного оборудования. Одним из факторов, оказывающих влияние на скорость коррозии, является температура. Наиболее остро данный аспект проявляется в нефтегазодобывающей промышленности при проведении кислотных обработок высокотемпературных скважин, где температура на забое может достигать $130-140{ }^{\circ} \mathrm{C}$, что в конечном счете приводит к разрушению подземного оборудования скважин и частичной нейтрализации кислоты в колонне насосно-компрессорных труб. Одними из эффективных ингибиторов коррозии, применяемых в высокотемпературных условиях в кислых средах, являются композиции на основе непредельных спиртов или $\alpha, \beta$-непредельных альдегидов, которые в смеси с азотсодержащими соединениями (ЧАС, первичные, вторичные и третичные амины) и рядом неорганических катионов позволяют защищать металл вплоть до температур порядка $250{ }^{\circ} \mathrm{C}$ [1]. В данной работе исследовали композиции: СолИнг ИК-1 (основа - ненасыщенный спирт в смеси с серосодержащим амидом в водной среде); ИК-2 (основа - непредельный спирт с усиливающими добавками четвертичной соли аммония и комплек- сона); ИК-3 (основа - ненасыщенный спирт в системе органических растворителей), а также СолИнг ИК-4(А) (основа - высокомолекулярное азотсодержащее ПАВ молекулярной массой от 300 до 400 с усиливающими добавками ненасыщенного спирта в системе органических растворителей) и ИК-4(Б) на основе высокомолекулярного азотсодержащего ПАВ с молекулярной массой до 300. Высокие адсорбционные и защитные свойства данных композиций в растворах соляной и серной кислот в условиях комнатных температур были показаны ранее в работах [2-6]. Представляется целесообразным оценить защитное действие данных композиций в условиях повышенных температур.

\section{МЕТОДИКА ЭКСПЕРИМЕНТА}

Исследования проводили в водных раствоpax $\mathrm{HCl}$ и $\mathrm{H}_{2} \mathrm{SO}_{4}$ концентрации 1 моль/л. Растворы готовили из реактивов марки «х.ч.» на дистиллированной воде. Дозировка ингибиторов коррозии составляла 0,1 г/л. Электроды для коррозионных испытаний были изготовлены из прута стали Ст3 состава, \% мас.: $\mathrm{Fe}-98,36 ; \mathrm{C}-0,2 ; \mathrm{Mn}-0,5 ; \mathrm{Si}-0,15$; $\mathrm{P}-0,04 ; \mathrm{S}-0,05 ; \mathrm{Cr}-0,3 ; \mathrm{Ni}-0,2 ; \mathrm{Cu}-0,2$. Площадь рабочей поверхности составляла $0,78 \mathrm{~cm}^{2}$.

Электрохимические исследования осуществляли на неподвижном электроде, армированном в эпоксидную смолу. Перед измерениями электрод зачищали на мелкозернистой шлифовальной 
бумаге, промывали дистиллированной водой, обезжиривали и выдерживали в рабочем растворе 1 ч до установления постоянного значения $(\Delta \mathrm{E}$ не более $5 \mathrm{mB}$ за последние 10 мин) потенциала коррозии Е. Квазистационарные поляризационные кривые снимали при температурах $20-60{ }^{\circ} \mathrm{C}$ в трехэлектродной ячейке ходом из катодной области в анодную со скоростью развертки потенциала $10 \mathrm{MB} / \mathrm{Mин}$, используя электрохимический измерительный комплекс фирмы SOLARTRON 1280 C (Великобритания). Электрод сравнения - насыщенный хлоридсеребряный, вспомогательный электрод - платиновый. Потенциалы приведены относительно стандартного водородного электрода. Термостатирование ячейки для измерений осуществлялось с помощью циркуляционного водяного термостата LOIP серии LT-100, контроль температуры непосредственно в ячейке осуществляли с помощью лабораторного термометра, точность поддержания температуры в ячейке составила $\pm 1{ }^{\circ} \mathrm{C}$.

Защитное действие $\left(Z_{\text {эл/ }}\right)$ определяли по формуле:

$$
Z=\frac{\left(i_{0}-i_{\text {инг }}\right) \times 100 \%}{i_{0}},
$$

где $\mathrm{i}_{0}, \mathrm{i}_{\text {инг }}$ - ток коррозии соответственно в чистом растворе и с добавкой ингибиторов, $\mathrm{A} / \mathrm{M}^{2}$. Ток кор-

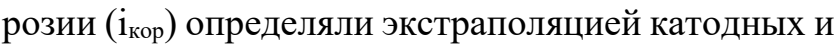
анодных Тафелевых участков на потенциал коррозии.

Изучение температурной зависимости скорости электрохимической коррозии стали позволяет лучше понять ее природу, так как температура изменяет скорость диффузии, перенапряжение электродных процессов, степень анодной пассивности, растворимость деполяризаторов и продуктов коррозии.

При концентрационной поляризации или замедленной стадии разряда влияние температуры на плотность тока описывается уравнением, аналогичным уравнению Аррениуса [7]. Таким образом, при построении графиков в координатах $\operatorname{lgi}$ кор $_{\text {, }} \mathrm{T}^{-1}$ получается прямая линия, а энергия активации электрохимической реакции находится из величины углового коэффициента прямой, равного

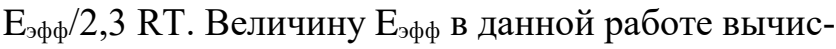
ляли как среднее значение на основании трех независимых испытаний.

При измерениях и обработке данных поляризационных измерений использовали программы CorrWare2, ZPlot2, ZView2 (Scribner Associates, Inc.).

\section{РЕЗУЛЬТАТЫ И ИХ ОБСУЖДЕНИЕ}

Известно, что для большинства ингибиторов изменение температуры раствора неоднозначно влияет на ингибирующий эффект. Снижение ингибирующего действия ПАВ с повышением температуры сменяется его ростом [8-19]. Дальнейшее повышение температуры может снова привести к уменьшению защитного действия. Это связано с разной природой адсорбции ПАВ в различных температурных интервалах. Физическая адсорбция ПАВ, уменьшающаяся с ростом температуры, сменяется хемосорбцией, характеризующейся симбатной зависимостью ингибиторного эффекта и температуры. С дальнейшим повышением температуры коэффициент торможения может снова уменьшиться, что обычно связывают с десорбцией ПАВ с поверхности металлического электрода. Температурный максимум ингибиторного эффекта впервые был обнаружен для ингибиторов коррозии сталей в кислых средах. Для большинства ингибиторов максимум лежит в пределах $60-80{ }^{\circ} \mathrm{C}$.

Типичные квазистационарные поляризационные кривые в растворах $1 \mathrm{M} \mathrm{HCl} \mathrm{и} \mathrm{H}_{2} \mathrm{SO}_{4}$ в отсутствие защитных композиций и с добавками композиций СолИнг ИК-2 и ИК-4(А) приведены на рис. 1, а результаты расчетов коррозионно-электрохимических характеристик стали в присутствии всех ингибиторов - в таблице 1. Как видно из полученных результатов, рост температуры не оказывает существенного влияния на величину потенциала коррозии, а также на наклон катодных и анодных Тафелевых участков, при этом с ростом температуры на каждые $10{ }^{\circ} \mathrm{C}$ величина тока коррозии возрастает в 2-4 раза (табл. 1), что согласуется с правилом ВантГоффа. Введение защитных композиций в растворы кислот в концентрации 0,1 г/л приводит к снижению токов коррозии, а при температуре до $40^{\circ} \mathrm{C}$ к увеличению наклонов соответствующих Тафелевых участков. Во всем исследованном диапазоне температур композиции СолИнг ИК-2, ИК-4(А) и ИК-4(Б) обладают высоким защитным эффектом, что говорит об устойчивости адсорбционных слоев данных ингибиторов с повышением температуры. Композиции ИК-1 и ИК-3 обладают меньшим защитным эффектом, что может объясняться более «бедным» составом композиций, но в целом рост температуры не оказывает сильного негативного влияния на величину защитного эффекта для данных композиций. 


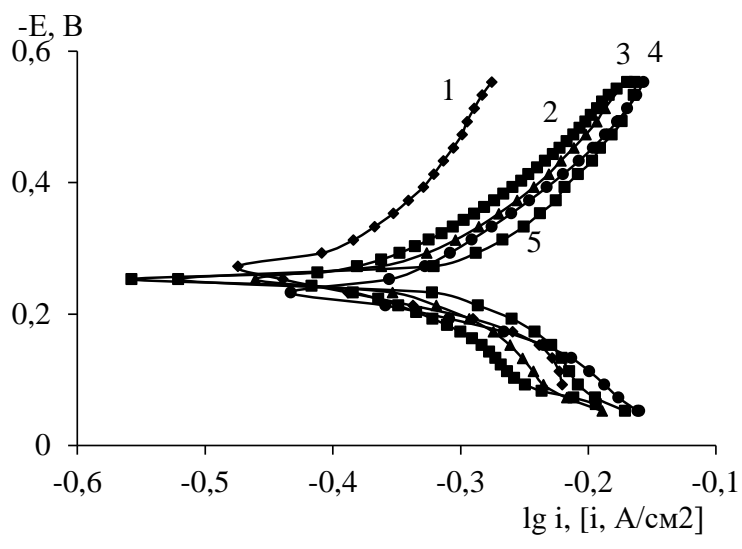

a

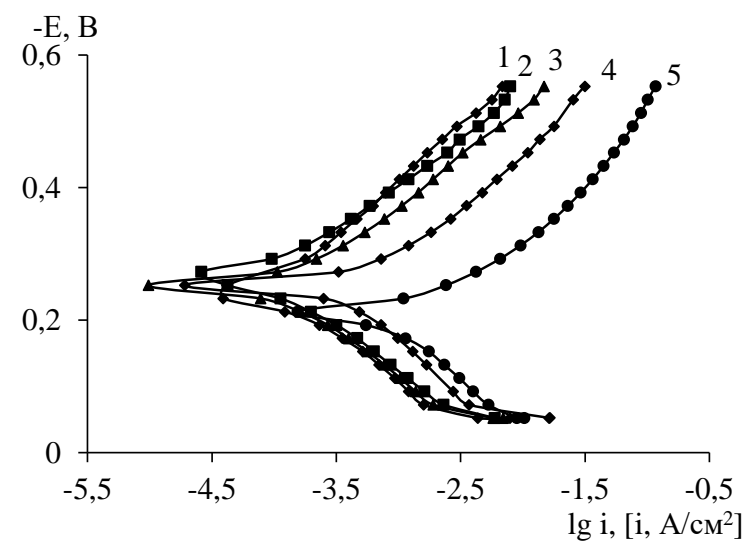

B

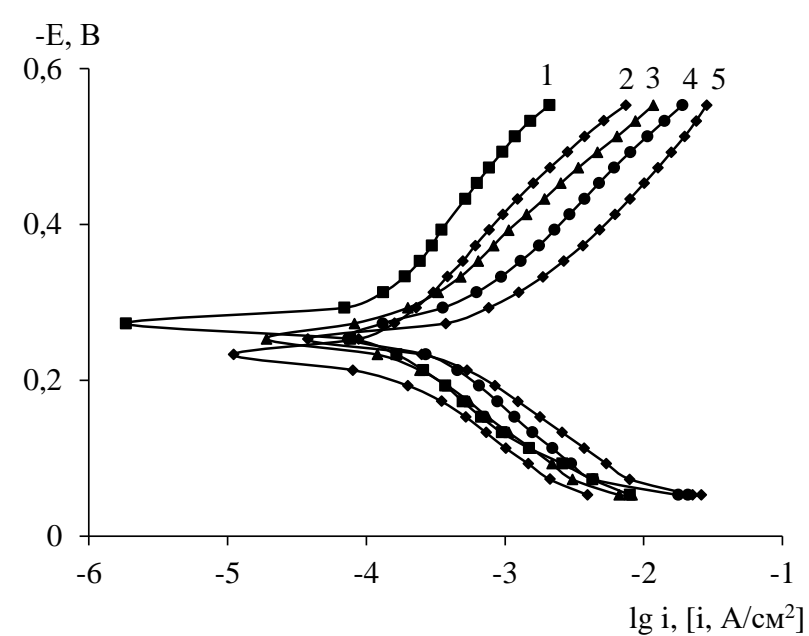

д

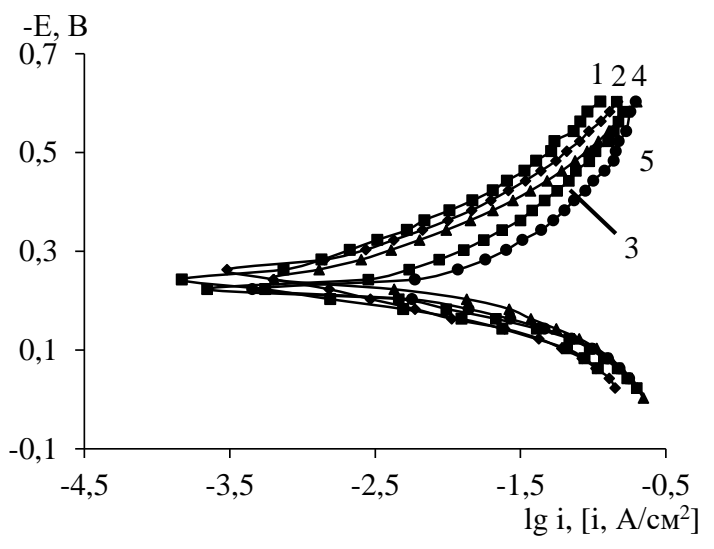

6
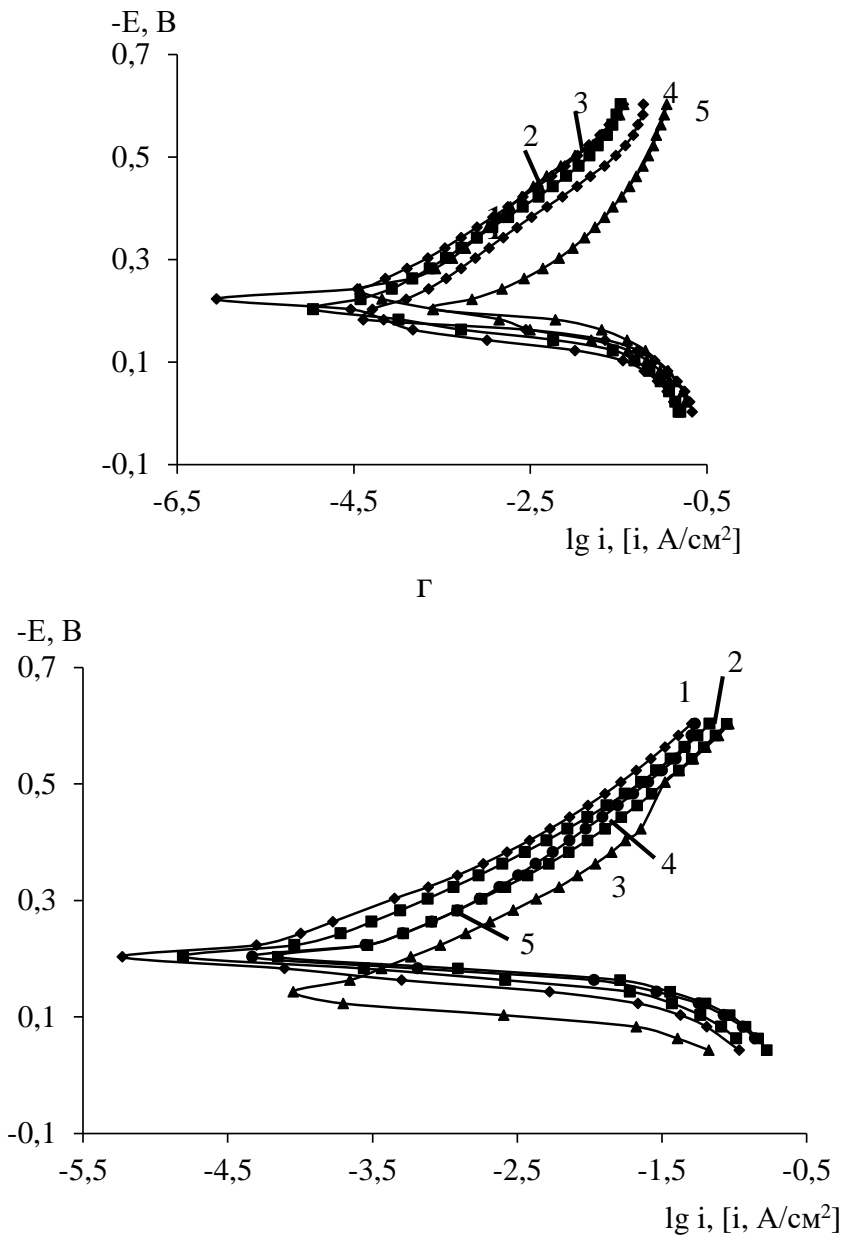

$\mathrm{e}$

Рис. 1. Поляризационные кривые Ст3 в $1 \mathrm{M} \mathrm{HCl}(\mathrm{a}, \mathrm{B}, \Gamma)$ и $1 \mathrm{M} \mathrm{H}_{2} \mathrm{SO}_{4}\left(\right.$ б,д,е) при температуре: $1-20^{\circ} \mathrm{C}, 2-30{ }^{\circ} \mathrm{C}, 3-40^{\circ} \mathrm{C}, 4-50{ }^{\circ} \mathrm{C}$, 5 - $60{ }^{\circ} \mathrm{C}$; а,б - без ингибитора; в,д - 0,1 г/л ИК-2; г,е - 0,1 г/л ИК-4(А)

Fig. 1. Polarization curves for mild steel in $1 \mathrm{M} \mathrm{HCl}($ а,в,г $)$ and $1 \mathrm{M} \mathrm{H}_{2} \mathrm{SO}_{4}\left(\right.$ б,д,e) at temperatures: $1-20{ }^{\circ} \mathrm{C}, 2-30{ }^{\circ} \mathrm{C}, 3-40{ }^{\circ} \mathrm{C}, 4-50{ }^{\circ} \mathrm{C}$, $5-60{ }^{\circ} \mathrm{C}$; а, б - without inhibitor; в,Д - with $0.1 \mathrm{~g} / \mathrm{l}$ of inhibitor IK-2; г,e -with $0.1 \mathrm{~g} / 1$ of inhibitor IK-4(A)

Обычно в случае применения ингибиторов - индивидуальных соединений рост температуры приводит к снижению адсорбции и, соответственно, снижению Z. Однако в нашем случае ингибиторы СолИнг представляют смесь органических соединений и не исключено, что при повышении темпе- ратуры раствора на поверхности металла возникают дополнительные центры адсорбции, что и приводит к росту Z. Однако, одновременно возрастающие колебания адсорбированных молекул вызывают и их частичную десорбцию, и при определенных температурах второй эффект начинает пре- 
обладать. Вероятно, это явление и объясняет неоднозначную зависимость защитного действия с повышением температуры. Кроме того, поскольку ингибиторы СолИнг являются смесью различных соединений, то в их состав входят вещества, адсорбирующиеся либо за счет хемосорбции, либо за счет физической адсорбции, а эти процессы по-разному зависят от температуры.

Эффективность исследуемых композиций объясняется наличием в их составе ненасыщенных спиртов, которые уже давно привлекли к себе внимание в связи с их высокими защитными характеристиками при повышенных температурах [1]. Известно, что химические превращения и полимеризация непредельных соединений в коррозионной среде в ряде случаев приводят к формированию ими на поверхности металла гидрофобной защитной пленки, существенно замедляющей коррозию. Согласно адсорбционно-полимеризационной теории, специфически адсорбирующиеся на поверхности металла молекулы непредельного ингибитора вступают в реакцию с аналогичными молекулами в растворе, что может привести к формированию на металле защитной пленки полимера [1]. Как видно из полученных данных, усложнение композиций наличием в составе азотсодержащих органических соединений приводит к более высоким величинам защитного действия Z.

На основе полученных данных величин коррозионных токов были построены зависимости тока коррозии от температуры, исходя из которых рассчитаны величины энергии активации коррозионного процесса. Зависимости lgi $=\mathrm{f}(1 / \mathrm{T})$ для чистых $1 \mathrm{M} \mathrm{HCl}$ и $\mathrm{H}_{2} \mathrm{SO}_{4}$ и в присутствии 0,1 г/л наиболее эффективного ингибитора ИК-4(А) представлены на рис. 2. Полученные значения энергии активации коррозионного процесса 42,2士1 и $48,2 \pm 1$ кДж/моль соответственно в чистых растворах соляной и серной кислот (табл. 2) указывают на активационный характер коррозионного процесса, так как в случае концентрационной или диффузионной поляризации Еэфф. составляет 8 - 25 кДж/моль, а при замедленном разряде - 40-120 кДж/моль [20]. Введение ингибиторов в растворы кислот в большинстве случаев не оказывает сильно выраженного влияния на величину энергии активации. Не-

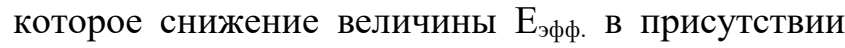
ряда защитных композиций (табл. 2) может свидетельствовать об усилении диффузионной составляющей, что связано с формированием на поверхности электрода защитной пленки ингибитора, которая препятствует проникновению $\mathrm{H}_{3} \mathrm{O}^{+}$-деполяризатора к поверхности металла. В указанных случаях энергия активации составила от 27 до 36 кДж/моль.
Коррозионно-электрохимические характеристики Ст3-электрода в 1M HCl и в $1 \mathrm{M} \mathrm{H}_{2} \mathrm{SO}_{4}$ без ингибиторов и в присутствии 0,1 г/л защитных композиций СолИнг

Table 1. Electrochemical parameters of mild steel in $1 \mathrm{M}$ $\mathrm{HCl}$ and in $1 \mathrm{M} \mathrm{H}_{2} \mathrm{SO}_{4}$ without inhibitors and with $0.1 \mathrm{~g} / \mathrm{l}$ of inhibitors Soling

\begin{tabular}{|c|c|c|c|c|c|}
\hline \multirow{2}{*}{$\begin{array}{l}\text { Инги- } \\
\text { битор }\end{array}$} & \multirow{2}{*}{$\begin{array}{l}\text { Темпера- } \\
\text { тура, }{ }^{\circ} \mathrm{C}\end{array}$} & \multicolumn{2}{|c|}{$1 \mathrm{M} \mathrm{HCl}$} & \multicolumn{2}{|c|}{$1 \mathrm{M} \mathrm{H}_{2} \mathrm{SO}_{4}$} \\
\hline & & $\mathrm{i}_{\text {corr }}, \mathrm{A} / \mathrm{M}^{2}$ & $\mathrm{Z}_{\mathrm{g} / \mathrm{x}}, \%$ & $\mathrm{i}_{\text {corr }}, \mathrm{A} / \mathrm{M}^{2}$ & $\mathrm{Z}_{\mathrm{g} / \mathrm{x}}, \%$ \\
\hline \multirow[t]{5}{*}{ 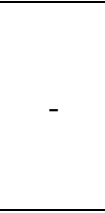 } & 20 & 2,87 & - & 6,26 & - \\
\hline & 30 & 6,2 & - & 11,71 & - \\
\hline & 40 & 11,9 & - & 20,97 & - \\
\hline & 50 & 12,6 & - & 27,25 & - \\
\hline & 60 & 26,9 & - & 81,13 & - \\
\hline \multirow{5}{*}{ ИК-1 } & 20 & 2,55 & 11,1 & 0,51 & 91,9 \\
\hline & 30 & 3,38 & 45,5 & 2,28 & 80,6 \\
\hline & 40 & 3,67 & 69,3 & 3,80 & 81,9 \\
\hline & 50 & 7,24 & 42,7 & 4,80 & 82,4 \\
\hline & 60 & 11,19 & 58,3 & 7,06 & 91,3 \\
\hline \multirow{5}{*}{ ИК-2 } & 20 & 0,97 & 66,2 & 0,44 & 92,9 \\
\hline & 30 & 1,03 & 83,4 & 0,79 & 93,2 \\
\hline & 40 & 1,49 & 87,5 & 1,17 & 94,4 \\
\hline & 50 & 3,52 & 72,2 & 1,61 & 94,1 \\
\hline & 60 & 9,63 & 64,1 & 9,80 & 87,9 \\
\hline \multirow{5}{*}{ ИК-3 } & 20 & 1,18 & 58,7 & 2,64 & 57,9 \\
\hline & 30 & 4,21 & 32,1 & 3,64 & 68,9 \\
\hline & 40 & 4,16 & 65,1 & 5,27 & 74,9 \\
\hline & 50 & 9,56 & 24,3 & 5,53 & 79,7 \\
\hline & 60 & 11,48 & 57,2 & 12,05 & 85,2 \\
\hline \multirow{5}{*}{$\begin{array}{l}\text { ИК- } \\
\text { 4(А) }\end{array}$} & 20 & 1,15 & 59,9 & 0,35 & 94,4 \\
\hline & 30 & 1,35 & 78,2 & 0,91 & 92,2 \\
\hline & 40 & 1,82 & 84,8 & 1,38 & 93,4 \\
\hline & 50 & 3,76 & 70,2 & 3,24 & 88,1 \\
\hline & 60 & 4,89 & 81,8 & 4,37 & 94,6 \\
\hline \multirow{5}{*}{$\begin{array}{l}\text { ИК- } \\
4(Б)\end{array}$} & 20 & 1,28 & 55,2 & 0,40 & 93,6 \\
\hline & 30 & 1,38 & 77,8 & 1,24 & 89,4 \\
\hline & 40 & 2,02 & 83,1 & 2,91 & 86,1 \\
\hline & 50 & 3,30 & 73,9 & 2,97 & 89,1 \\
\hline & 60 & 4,97 & 81,5 & 7,02 & 91,3 \\
\hline
\end{tabular}

таблица 2

Рассчитанные значения энергии активации коррозии в растворах $1 \mathrm{M} \mathrm{HCl}$ и $1 \mathrm{M} \mathrm{H}_{2} \mathrm{SO}_{4}$ без добавок и с добавкой 0,1 г/л защитных композиций СолИнг

Table 2. Calculated values of the activation energy of corrosion process in $1 \mathrm{M} \mathrm{HCl}$ and in $1 \mathrm{M} \mathrm{H}_{2} \mathrm{SO}_{4}$ without inhibitors and with $0.1 \mathrm{~g} / \mathrm{l}$ of inhibitors Soling

\begin{tabular}{|c|c|c|}
\hline \multirow{2}{*}{ Ингибитор } & \multicolumn{2}{|c|}{$\mathrm{E}_{\text {акт, }}$ кДж/моль } \\
\cline { 2 - 3 } & $1 \mathrm{M} \mathrm{HCl}$ & $1 \mathrm{M} \mathrm{H}_{2} \mathrm{SO}_{4}$ \\
\hline- & $42,2 \pm 1$ & $48,2 \pm 1$ \\
\hline ИК-1 & $29,9 \pm 1$ & $49,3 \pm 1$ \\
\hline ИК-2 & $46,5 \pm 1$ & $33,8 \pm 1$ \\
\hline ИК-3 & $43,8 \pm 1$ & $27,8 \pm 1$ \\
\hline ИК-4(А) & $31,6 \pm 1$ & $51,4 \pm 1$ \\
\hline ИК-4(Б) & $36,3 \pm 1$ & $53,9 \pm 1$ \\
\hline
\end{tabular}




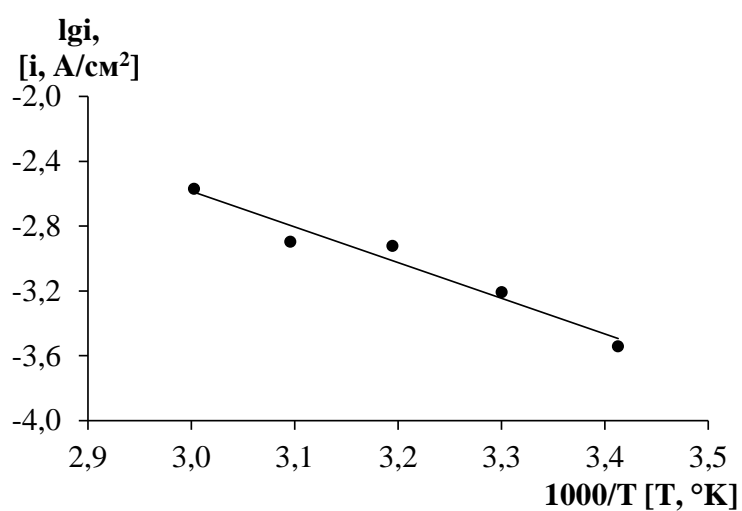

a

lgi,

$\left[\mathbf{i}, \mathbf{A} / \mathbf{c m}^{2}\right]$

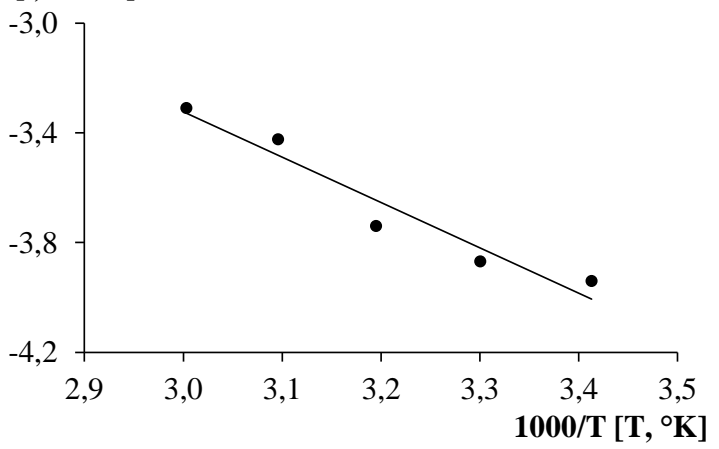

B

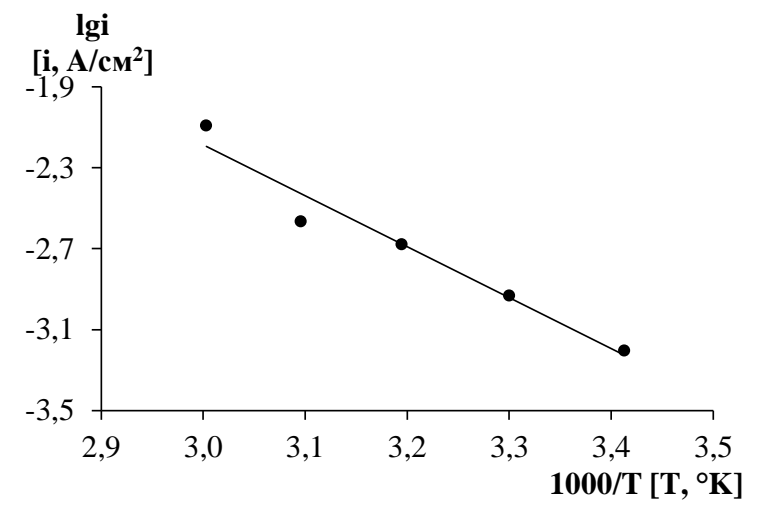

б

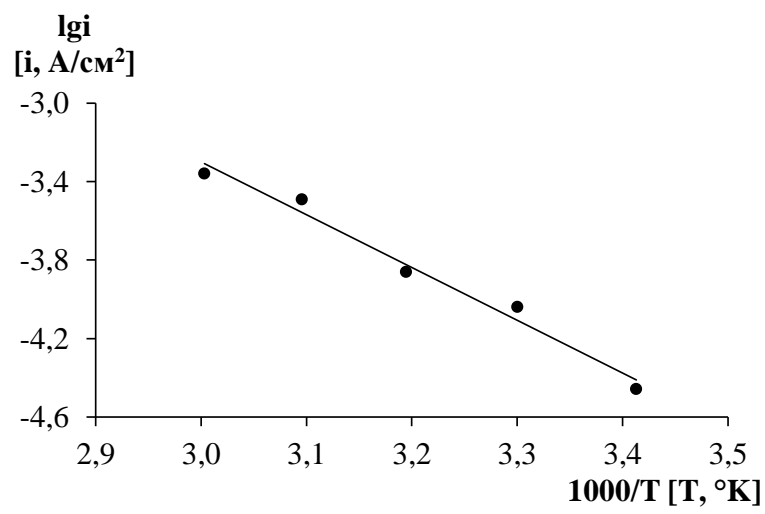

$\Gamma$

Рис. 2. Зависимость скорости коррозии от температуры в растворах $1 \mathrm{M} \mathrm{HCl}(\mathrm{a}, \mathrm{B})$ и $1 \mathrm{M} \mathrm{H}_{2} \mathrm{SO}_{4}($ б,г) без ингибиторов (а,б) и с добавкой 0,1 г/л ингибитора ИК-4(А) (в,г)

Fig. 2. The dependence of corrosion rate on the temperature in $1 \mathrm{M} \mathrm{HCl}(\mathrm{a}, \mathrm{B})$ and $1 \mathrm{M} \mathrm{H}_{2} \mathrm{SO}_{4}($ б,г)without inhibitors $(\mathrm{a}, \bar{\sigma})$ and with $0.1 \mathrm{~g} / \mathrm{l}$ of inhibitor IK-4(A) $(\mathrm{B}, \Gamma)$

\section{ВЫВОДЫ}

Исследован ряд ингибиторов коррозии «СолИнг», на основе непредельных спиртов и азотсодержащих соединений различного строения. С повышением температуры практически все защитные композиции сохраняют защитное действие, при этом степень защиты стали в отдельных температурных интервалах увеличивается. Для ряда композиций тенденция к наращиванию защитных свойств с ростом температуры в $1 \mathrm{M} \mathrm{HCl}$ ограничивается небольшим температурным интервалом (20$40{ }^{\circ} \mathrm{C}$, композиции ИК-1, 2 и 3). В $1 \mathrm{M} \mathrm{H}_{2} \mathrm{SO}_{4}$ исследуемые составы проявляют в основном высокий защитный эффект, слабо зависящий от температуры. Наиболее эффективными композициями для защиты стали в указанных средах являются ИК-2, ИК-4(А) и ИК-4(Б), для которых достигается (в среднем) степень защиты стали более $80 \%$ в растворе соляной кислоты и более $90 \%$ в растворе серной кислоты.

На основе полученных результатов обработки поляризационных кривых были рассчитаны эффективные энергии активации коррозионного процесса. Полученные значения Еэфф в чистых кислотах и в ряде случаев в присутствии защитных композиций говорят об активационном характере процесса. С введением композиций в ряде случаев

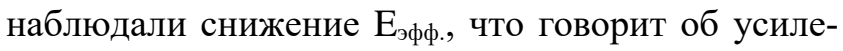
нии диффузионной составляющей процесса ввиду формирования устойчивых адсорбционных слоев ингибитора.

Таким образом, композиции СолИнг ИК-1, $2,3,4$ (А) и 4(Б) могут быть применимы в качестве ингибиторов коррозии в растворах соляной и серной кислот при повышенных температурах. 


\section{ЛИТ ЕР А Т У Р А}

1. Авдеев Я.Г., Кузнецов Ю.И. Физико-химические аспекты ингибирования кислотной коррозии металлов ненасыщенными органическими соединениями. Успехи химии. 2012. Т. 81. № 12. C. 1133-1145. DOI: 10.1070/RC2012v081n12ABEH004292.

2. Меньшиков И.А., Лукьянова Н.В., Шеин А.Б. Исследование коррозионно-электрохимического поведения малоуглеродистой стали в растворах соляной кислоты в присутствии ингибиторов коррозии «СОЛИНГ». Вестн. Перм. ун-та. Сер.: Химия. 2016. № 3 (23). C. 40-46. DOI: 10.17072/22231838-2016-3-40-46.

3. Менышиков И.А., Шеин А.Б., Лукьянова Н.В. Исследование адсорбционных свойств ингибиторов коррозии СолИнг в соляной кислоте методом спектроскопии импеданса. Коррозия: материаль, защитта. 2017. №7. С.29-34.

4. Меньшиков И.А., Шеин А.Б. Защита от коррозии малоуглеродистой стали в кислых средах ингибиторами серии СОЛИНГ. Изв. вузов. Химия и хим. технология. 2016. Т. 59. Вып. 2. С. 70-73.

5. Меньшиков И.А., Шеин А.Б. Защитные свойства ингибиторов серии СОЛИНГ в кислых сероводородсодержащих средах. Изв. вузов. Химия и хим. технология. 2018. Т. 61. Вып. 7. С. 91-98. DOI: 10.6060/ivkkt.20186107.5703.

6. Menshikov I.A., Shein A.B., Lukuanova N.V. Studying the adsorption properties of the Soliig corrosion inhibitor in hydrochloric acid by the method of impedance spectroscopy. Protect. Metal. Phys. Chem. Surf. 2018. V. 54. N 7. P. 1292-1297. DOI: 10.1134/S2070205118070146.

7. Горбачев С.В. Влияние температуры на электролиз, как кинетический метод исследования природы электрохимических процессов. Четвертое совещание по электрохимии. Сб. научных трудов. М.: Изд. АН СССР. 1959. С. 61-71.

8. Авдеев Я.Г., Тюрина М.В., Лучкин А.Ю., Кузнецов Ю.И. Об ингибировании коррозии низкоуглеродистой стали в лимоннокислых растворах. Вестн. Тамбов. унma. 2013. Т. 18. № 5. С. 2262-2265.

9. Авдеев Я.Г. О классификации ацетиленовых ингибиторов кислотной коррозии железа. Коррозия: материаль, зашчита. 2006. № 1. С. 18-24.

10. Подобаев Н.И., Авдеев Я.Г. Ацетиленовые соединения как ингибиторы кислотной коррозии железа. Обзор. $3 a$ щчита металлов. 2004. Т. 40. № 1. С. 11-18.

11. Авдеев Я.Г., Лучкин А.Ю., Кузнецов Ю.И., Горичев И.Г., Тюрина М.В. Защита низкоуглеродистой стали в сернокислых растворах от высокотемпературной коррозии (до $200{ }^{\circ} \mathrm{C}$ ). Коррозия: материальл, защитат. 2011. № 8. С. 20-26.

12. Авдеев Я.Г., Лучкин А.Ю., Кузнецов Ю.И., Горичев И.Г., Тюрина М.В. Защита низкоуглеродистой стали в солянокислых растворах от высокотемпературной коррозии (до $160{ }^{\circ} \mathrm{C}$ ). Коррозия: материаль, зашита. 2011. № 10. С. 26-31.

13. Атари Г., Сачхен Х.П., Шивакумара С., Наик Я.А., Венкатеша Т.В. Обработка поверхности цинка основаниями Шиффа и исследование его коррозии. Электрохимия. 2007. Т. 43. №7. С.886-892.

14. Quraishi M.A., Rawat J. Corrosion inhibiting action of tetramethyl-dithia-octaaza-cyclotetradeca-hexaene (MTAH) on corrosion of mild steel in hot 20\% sulfuric acid. Mater. Chem. Phys. 2003. V. 77. N 1-2. P. 43-47. DOI: 10.1016/S0254-0584(01)00576-4.

\section{REFERENCES}

1. Avdeev Y.G., Kuznetsov Yu.I. Physicochemical aspects of inhibition of acid corrosion of metals by unsaturated organic compounds. Usp. Khim. 2012. V. 81. N 12. P. 1133-1145 (in Russian). DOI: 10.1070/RC2012v081n12ABEH004292.

2. Menshikov I.A., Lukyanova N.V., Shein A.B. Investigation of electrochemical and corrosion behaviour of mild steel in hydrochloric acid solutions in the presence of inhibitors «Soling». Vestn. Perm. Un-ta. Khimiya. 2016. N 3(23). P. 40-46 (in Russian). DOI: 10.17072/2223-1838-2016-3-40-46.

3. Menshikov I.A., Shein A.B., Lukyanova N.V. Investigation of adsorption properties of corrosion inhibitors SolIng in hydrochloric acid by electrochemical impedance spectroscopy method. Korroziya: Materially, Zaschita. 2017. N 7. P. 29-34 (in Russian).

4. Menshikov I.A., Shein A.B. Corrosion protection of low-carbon steel in acidic media by inhibitors of SOLING series. Izv. Vyssh. Uchebn. Zaved. Khim. Khim. Tekhnol. 2016. V. 59. N 2. P. 70-73 (in Russian).

5. Menshikov I.A., Shein A.B. Protective properties of «SOLING» series inhibitors in acidic media containing hydrogen sulphide. I $z v$. Vyssh. Uchebn. Zaved. Khim. Khim. Tekhnol. 2018. V. 61. N 7. P. 91-98 (in Russian). DOI: 10.6060/ivkkt.20186107.5703.

6. Menshikov I.A., Shein A.B., Lukuanova N.V. Studying the adsorption properties of the Soliig corrosion inhibitor in hydrochloric acid by the method of impedance spectroscopy. Protect. Metal. Phys. Chem. Surf. 2018. V. 54. N 7. P. 1292-1297. DOI: $10.1134 /$ S2070205118070146.

7. Gorbachev S.V. The influence of the temperature on the electrolysis as the kinetic method of the investigation of the nature of electrochemical processes. 4th Soveschanie po elektrokhimii. Sbornik nauchnukh trudov. M.: Izd. Akademii Nauk SSSR. 1959. P. 61-71 (in Russian).

8. Avdeev Ya.G., Tyurina M.V., Luchkin A.Yu., Kuznetsov Yu.I. Inhibition of corrosion of mild steel in solutions of citric acid. Vestn. Tambov. Un-ta. 2013. V. 18. N 5. P. 2262-2265 (in Russian).

9. Avdeev Ya.G. On the classification of acetylenic inhibitors of acid corrosion of iron. Korroziya: Materially, Zaschita. 2006. N 1. P. 18-24 (in Russian).

10. Podobaev N.I., Avdeev Ya.G. A review of acetylene compounds as inhibitors of acid corrosion of iron. Protection of Metals and Physical Chemistry of Surfaces. 2004. V. 40. N 1. P. 7-13.

11. Avdeev Ya.G., Luchkin A.Yu., Kuznetsov Yu.I., Gorichev I.G., Tyurina M.V. Protection of low-carbon steel in sulfuric acid solutions against high-temperature corrosion (up to $200{ }^{\circ} \mathrm{C}$ ). Korroziya: Materially, Zaschita. 2011. N 8. P. 20-26 (in Russian).

12. Avdeev Ya.G., Luchkin A.Yu., Kuznetsov Yu.I., Gorichev I.G., Tyurina M.V. Protection of low-carbon steel in hydrochloric acid solutions against high-temperature corrosion (up to $160^{\circ} \mathrm{C}$ ). Korroziya: Materially, Zaschita. 2011. N 10. P. 26-31 (in Russian).

13. Atari G., Sachhen Kh.P., Shivakumara S., Naik Ya.A., Venkatesha T.V. Treatment of the zink surface by the Schiff bases and investigation of corrosion. Elektrokhimiya. 2007. V. 43. N 7. P. 886-892 (in Russian).

14. Quraishi M.A., Rawat J. Corrosion inhibiting action of tetramethyl-dithia-octaaza-cyclotetradeca-hexaene (MTAH) on corrosion of mild steel in hot 20\% sulfuric acid. Mater. Chem. Phys. 2003. V. 77. N 1-2. P. 43-47. DOI: 10.1016/S0254-0584(01)00576-4. 
15. Quraishi M.A., Ansari F.A. Corrosion inhibition by fatty acid triazoles for mild steel in formic acid. J. Appl. Electrochem. 2003. V. 33. N 3-4. P. 233-238. DOI: 10.1023/A:1024106123577.

16. Singh A.K., Quraishi M.A. Inhibitive effect of diethylcarbamazine on the corrosion of mild steel in hydrochloric acid. Corrosion Science. 2010. V. 52. N 4. P. 1529-1535. DOI: 10.1016/j.corsci.2009.12.011.

17. Quraishi M.A., Khan S. Inhibition of mild steel corrosion in sulfuric acid solution by thiadiazoles. J. Appl. Electrochem. 2006. V. 36. N 5. P. 539-544. DOI: 10.1007/s10800-005-9087-6.

18. Плотникова М.Д., Шеин А.Б. Защита стали от сероводородной коррозии ингибиторами «ФЛЭК» при повышенных температурах. Изв. вузов. Химия и хим. технология. 2014. Т. 57. Вып. 1. С. 91-96.

19. Finšgar M., Jackson J. Application of corrosion inhibitors for steels in acidic media for the oil and gas industry: A review. Corrosion Science. 2014. V. 86. P. 17-41. DOI: 10.1016/j.corsci.2014.04.044.

20. Михайлов Б.Н., Немыкина О.В. Определение эффективной энергии активации коррозионного процесса. Ползунов. вестн. 2009. № 3. С. 135-136.
15. Quraishi M.A., Ansari F.A. Corrosion inhibition by fatty acid triazoles for mild steel in formic acid. J. Appl. Electrochem. 2003. V. 33. N3-4. P. 233-238. DOI: 10.1023/A:1024106123577.

16. Singh A.K., Quraishi M.A. Inhibitive effect of diethylcarbamazine on the corrosion of mild steel in hydrochloric acid. Corr. Sci. 2010. V. 52. N 4. P. 1529-1535. DOI: 10.1016/j.corsci.2009.12.011.

17. Quraishi M.A., Khan S. Inhibition of mild steel corrosion in sulfuric acid solution by thiadiazoles. J. Appl. Electrochem. 2006. V. 36. N 5. P. 539-544. DOI: 10.1007/s10800-005-9087-6.

18. Plotnikova M.D., Shein A.B. Steel protection from hydrogen sulfide corrosion with FLEK inhibitors at higher temperatures. Izv. Vyssh. Uchebn. Zaved. Khim. Khim. Tekhnol. 2014. V. 57. N 1. P. 91-96 (in Russian).

19. Finšgar M., Jackson J. Application of corrosion inhibitors for steels in acidic media for the oil and gas industry: A review. Corr. Scie. 2014. V. 86. P. 17-41. DOI: 10.1016/j.corsci.2014.04.044.

20. Mikhailov B.N., Nemykina O.V. The determination of the effective activation energy of the corrosion process. Polzunov. Vestn. 2009. N 3. P. 135-136 (in Russian).

Поступила в редакичию 13.11.2017

Принята к опубликованию 03.08.2018

Received 13.11.2017

Accepted 03.08.2018 